\title{
Lymphocytic gastritis and Helicobacter pylori infection in gastric lymphoma
}

\author{
A Miettinen, T J Karttunen, M Alavaikko
}

\begin{abstract}
Lymphocytic gastritis and primary gastric lymphoma are rare conditions with unknown aetiology. It has recently been suggested that Helicobacter pylori has a role in the pathogenesis of both of them. The occurrence of lymphocytic gastritis and $H$ pylori was studied in a series of patients with primary gastric lymphoma. The cases of primary gastric lymphomas $(n=35)$ diagnosed in years 1970-1993 were identified. The specimens of 22 cases contained gastric mucosa sufficiently so that the number of intraepithelial lymphocytes, severity of gastritis, and occurrence of $H$ pylori could be studied. Lymphocytic gastritis was detected in seven of 22 patients $(32 \%)$, and in most cases both in antral and body mucosa. Atrophy of the body glands was significantly more severe in lymphocytic gastritis patients. $H$ pylori was detected in 13 of all 22 patients (59\%); two of seven lymphocytic gastritis patients $(29 \%)$, and 11 of $15(73 \%)$ of patients without lymphocytic gastritis were $H$ pylori positive. Patients with gastric lymphoma have significantly increased prevalence of lymphocytic gastritis. Rarity of $H$ pylori in these patients might be connected with atrophic changes in body mucosa. Further studies are needed to show the significance of lymphocytic gastritis as a precursor of gastric lymphoma.

(Gut 1995; 37: 471-476)
\end{abstract}

Keywords: gastric lymphoma, Helicobacter pylori, lymphocytic gastritis, intraepithelial lymphocyte.

A process characterised by a heavy increase in intraepithelial lymphocytes in gastric mucosa was first described in 1985 by Haot et al ${ }^{1}$ and Rubio et $\mathrm{al}^{2}$ and later termed lymphocytic gastritis. The frequency of lymphocytic gastritis among unselected endoscopy patients has varied from $0 \cdot 8 \%$ to $4 \cdot 5 \%{ }^{3-5}$; lymphocytic gastritis is more common in coeliac disease. ${ }^{6}$ Significance of lymphocytic gastritis and aetiology are unknown, but abnormal reaction to some nutritional antigen or Helicobacter pylori has been suggested. ${ }^{3}$

Primary lymphoma of the gastric mucosa is a rare disease representing 1 to $5 \%$ of gastric malignancies, ${ }^{7-9}$ but the incidence is increasing. ${ }^{1011}$ Most gastric lymphomas arise from mucosa associated lymphatic tissue, ${ }^{12}$ but their aetiology is otherwise obscure. Recently Wotherspoon et al ${ }^{13}$ detected $H$ pylori infection in $92 \%$ of cases with gastric lymphoma and suggested that the infection may have a role in the pathogenesis of lymphoma.

As intraepithelial lymphocytes are speculated to have a role in the regulation of normal mucosal inflammatory reaction ${ }^{14} 15$ they may also participate in the pathogenesis of mucosal lymphoma, where abnormal antigen stimulation or abnormal regulation of the immune response is suspected to play an important part. ${ }^{16}$ Recently we saw a case of primary gastric lymphoma of B-cell type associated with $H$ pylori infection and heavy increase of intraepithelial T-lymphocytes fulfilling the criteria of lymphocytic gastritis. This finding prompted us to study a series of primary gastric lymphomas and evaluate the occurrence of lymphocytic gastritis and $H$ pylori infection. Clinical features and characteristics of gastric mucosa were analysed to understand the potential connection between lymphocytic gastritis and gastric lymphoma.

\section{Methods}

Patients

The study consisted of all patients diagnosed with primary gastric lymphoma in years 1970-1993 in the department of pathology, University of Oulu. Gastric lymphomas were regarded primary if the stomach was the only or most massively affected organ; no peripheral or mediastinal lymphadenopathy was present at the early stage of lymphoma and the leucocyte number in blood was within normal range. ${ }^{17}$

\section{Classification and staging of tumours}

The histological diagnosis was based on $4 \mu \mathrm{m}$ sections made from original formalin fixed, paraffin wax embedded specimens stained with haematoxylin and eosin. Additional sections were stained with L26 antibody (CD20; Dako, Copenhagen, Denmark) and UCHL1 (CD45RO); Dako, Copenhagen, Denmark), to verify cell lineage of tumour and intraepithelial lymphocytes.

Gastric lymphomas were typed according to the classification used by Isaacson et al. ${ }^{18}$ For staging, a modified Ann Arbor system was used. ${ }^{19-21}$

Information of clinical history and the localisation, size, and macroscopic appearance of lymphoma were collected from the patient records. Because the exact size of the tumours was mostly unknown, the cases were classified in three categories according to the approximate largest diameter: (a) small, diameter $1 \mathrm{~cm}$ or less; (b) middle sized, diameter 1 to $3 \mathrm{~cm}$; and (c) large, diameter $3 \mathrm{~cm}$ or more. 
TABLE I Histological typing of gastric lymphomas in patients with and without lymphocytic gastritis ( $L G)$.

'Unknown' category includes 13 cases where histological specimens did not represent gastric mucosa

\begin{tabular}{llll}
\hline Lymphoma type & LG & No LG & Unknown \\
\hline Low grade B cell lymphoma & 3 & 8 & 8 \\
High grade B cell lymphoma & 4 & 6 & 5 \\
Low grade T cell lymphoma & 0 & 1 & 0 \\
\hline
\end{tabular}

Estimation of intraepithelial lymphocyte numbers and diagnosis of lymphocytic gastritis

In each case the numbers of intraepithelial lymphocytes were estimated separately in antral mucosa, body mucosa, and near tumour using haematoxylin and eosin stained sections. Thickness of section may affect the assessment of objects of different sizes ${ }^{22}$ such as intraepithelial lymphocytes and epithelial cells. Therefore the uniformity of thickness was first verified by measuring section thickness with modified Small's method. ${ }^{22}$ Areas close to the tumour were avoided when counting antral and body intraepithelial lymphocytes and measurement was done at least $5 \mathrm{~mm}$ from the lateral margin of the tumour. In most cases the distance from the tumour was more than $1 \mathrm{~cm}$. Counting for areas close to the tumour was performed in surface and foveolar epithelium immediately above the tumour avoiding regions with erosions or direct epithelial infiltration of tumour cells. In each of the three regions 100 consecutive cells of surface and foveolar epithelium were counted in three randomly selected areas of surface and foveolar epithelium using haematoxylin and eosin stained sections. Lymphocytes forming lymphoepithelial lesions ${ }^{23}$ close to germinal centres or lymphoma infiltrate could be easily recognised and were not counted. Exclusion of cells forming lymphoepithelial lesions was based on several features. Intraepithelial lymphocytes were surrounded by a clear halo. Their nuclei were smaller and more roundish than in lymphocytes of lymphoepithelial lesions. Lymphocytes of lymphoepithelial lesions often formed groups of several cells while intraepithelial lymphocytes stayed mostly as single cells and were evenly distributed in foveolar and surface epithelium. Three counts from each area were pooled, and

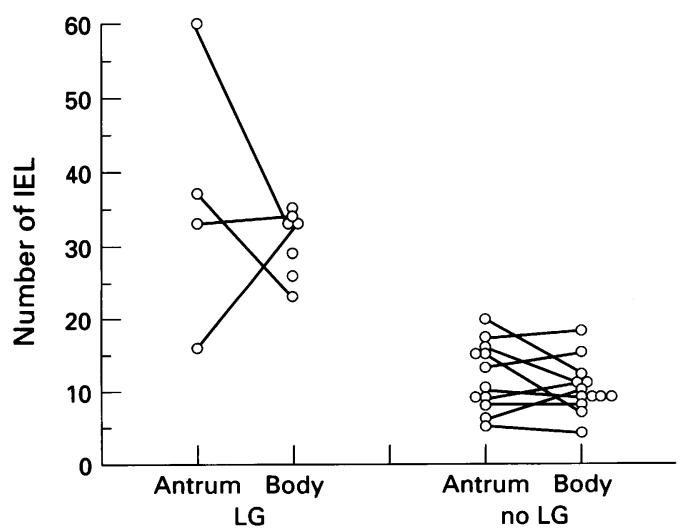

Figure 1: Number of intraepithelial lymphocytes in antrum and body in lymphoma patients with and without lymphocytic gastritis (LG). expressed as intraepithelial lymphocytes per 100 epithelial cells. As some cases with moderate diffuse increase of intraepithelial lymphocytes (25-30 intraepithelial lymphocyte/100 epithelial cells) showed heavy increase focally, the number of intraepithelial lymphocytes was additionally counted in the most affected areas.

Lymphocytic gastritis was diagnosed if the count of intraepithelial lymphocytes in antral or body mucosa distant to the area of lymphoma was $>30 / 100$ epithelial cells. ${ }^{24}$

\section{Estimation of severity of gastritis and occurrence of $\mathrm{H}$ pylori}

The severity of gastritis in antral and body mucosa was estimated by using a five point scale $^{25}$ from normal (grade 0), to superficial gastritis (grade 1); slight, moderate, and severe atrophic gastritis (grades 2,3 , and 4 ). The extent of intestinal metaplasia, the numbers of mononuclear inflammatory cells in lamina propria, neutrophilic leucocytes, and eosinophilic leucocytes were estimated in grades showing a spectrum from the normal state (grade 0) to slight (1), moderate (2), and heavy (3) increase. ${ }^{25}$ These gradations are closely comparable with those of the Sydney system. ${ }^{26}$

The presence of $H$ pylori was first studied using haematoxylin and eosin stained sections of antral and body mucosa. Cases negative in haematoxylin and eosin stainings were further analysed using the modified Giemsa staining. The quantity of $H$ pylor $i$ was graded according to Marshall et al ${ }^{27}$ using a four point scale from absent (grade 0) to abundant (grade 3).

\section{Results}

\section{Patients and histological types of primary gastric} lymphomas

There were 35 patients ( 63 median age, 27-85 range) with primary gastric lymphoma consisting of 15 women (65 median age, 28-79 range) and 20 men (56 median age, 27-85 range). Table I shows the distribution of lymphoma types. Immunohistochemical stainings showed in 33 cases features of B cell lymphomas (L26 positivity, UCHL1 negativity). One case was positive for UCHL1 and negative for L26 and was classified as a small cell pleomorphic type of T cell lymphoma. In one case material available for immunohistochemical stainings did not contain tumour tissue, and the case was classified as immunoblastic high grade type of B cell lymphoma according to haematoxylin and eosin staining.

The specimens of 13 patients represented neither antral or body mucosa; in these cases the presence or absence of gastritis or $H$ pylori could not be evaluated and these patients were excluded from the analysis. The samples of 22 patients were included; in 14 patients both antral and body mucosa outside lymphoma could be evaluated, in two patients only antral and in six patients only body mucosa could be studied. 


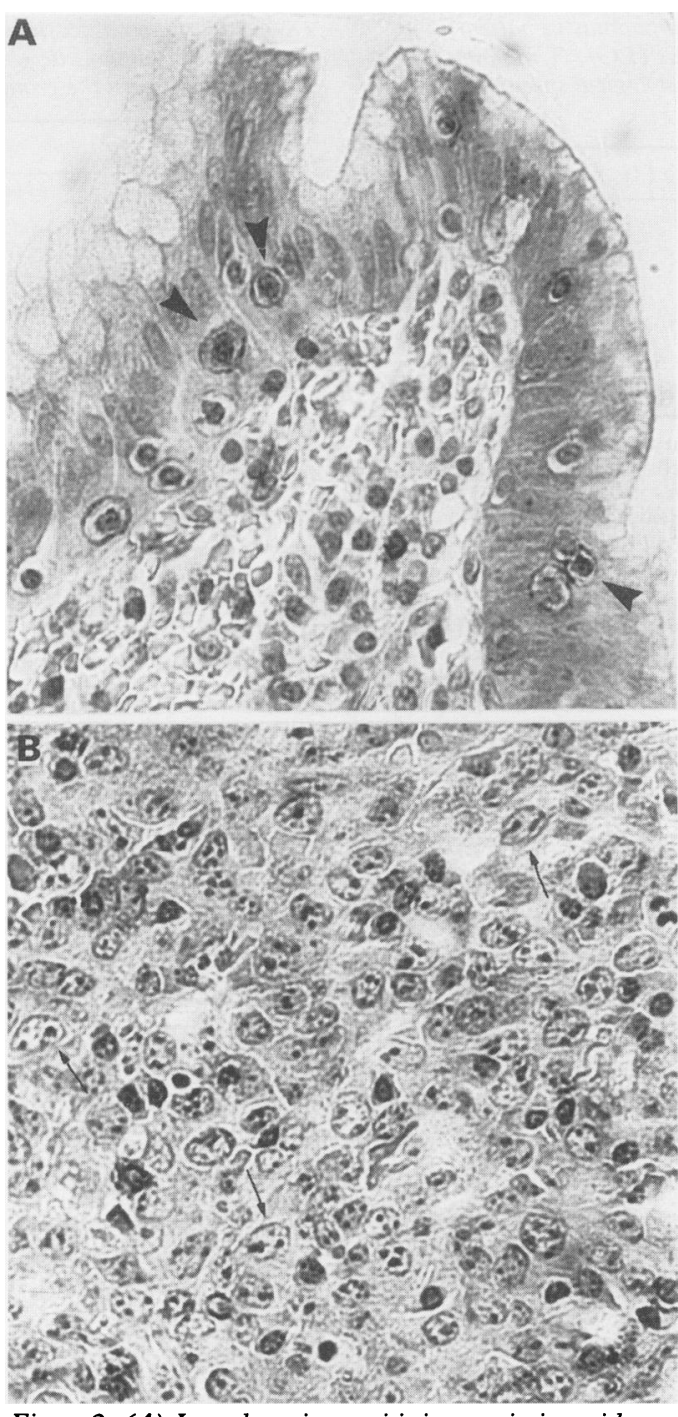

Figure 2: (A) Lymphocytic gastritis in association with gastric lymphoma. Most of the intraepithelial lymphocytes are UCHL1 positive (arrowheads). UCHL1,

magnification $\times 384$. (B) Lymphoma cells are not stained with UCHL1 (arrows). Same case as in (A). UCHL1, magnification $\times 384$.

Intraepithelial lymphocyte counts and occurrence of lymphocytic gastritis

There were seven of 22 patients (32\%) fulfilling the criteria of lymphocytic gastritis. ${ }^{24}$ In five of them a heavy diffuse increase of intraepithelial lymphocytes was present, as shown by occurrence of $>30$ intraepithelial lymphocytes in non-selected areas of antral or body mucosa. In two patients a moderate increase of intraepithelial lymphocytes (25-30/100) in random areas was accompanied with a heavy increase $(>30 / 100)$ in the most affected area of antral or body mucosa. All seven cases represented B cell lymphomas. Measured thickness of sections were similar both in patients with lymphocytic gastritis (mean (SD) $4.82 \mu \mathrm{m}(0.43)$; range $4 \cdot 0-5 \cdot 25)$ and without lymphocytic gastritis $(4 \cdot 88 \mu \mathrm{m}(0 \cdot 33) ; 4 \cdot 25-5 \cdot 25)$.

Usually the number of intraepithelial lymphocytes was roughly the same in all areas of the mucosa including the vicinity of the tumour. The number of intraepithelial lymphocytes in the antrum correlated with those in the body (Spearman rank correlation $0.534, \mathrm{p}=0.001$ ) and in the tumour area (Spearman 0.366, $p=0.05)$. Figure 1 shows the distribution of intraepithelial lymphocyte counts in nonselected areas of antral and body mucosa in patients with and without lymphocytic gastritis. The median number of intraepithelial lymphocytes close to the tumour was 34 (range 25-50) in patients with lymphocytic gastritis and 11 (8-22) without lymphocytic gastritis.

About $40-70 \%$ of intraepithelial lymphocytes were positive for UCHL1 (Fig 2A and B), while none of them were positive for L26 (Fig 3). Cells forming lymphoepithelial lesions were negative for UCHL1 and positive for L26.

No significant differences in size, stage or localisation of tumours with and without lymphocytic gastritis were seen (Tables II and III). Age and sex distribution and occurrence of other diseases were similar in patients with and without lymphocytic gastritis (Table IV).

\section{Severity of gastritis and occurrence of $\mathrm{H}$ pylori} infection

Gastritis was present in all patients. There were no significant differences in the numbers of eosinophilic granulocytes, lamina propria mononuclear inflammatory cells or intestinal metaplasia between patients with and without lymphocytic gastritis. There were more neutrophilic granulocytes in antral mucosa in patients with lymphocytic gastritis (median score 1.5 ; range $1-2$ ) than in patients without lymphocytic gastritis (median 1 ; range $0-2$; $\mathrm{p}=0.04$, Mann-Whitney test). In addition, more advanced body atrophy was present in patients with lymphocytic gastritis (median score 2; range 2-3) than in patients without lymphocytic gastritis (median 1 ; range 1-3; $p=0.01$; Figs 4 and 5). Association of intraepithelial lymphocyte numbers and severity of gastritis was also evident from correlation between body intraepithelial lymphocyte count and body gastritis (Spearman $r 0.452$, $\mathrm{p}=0.01)$, intestinal metaplasia $(r 0.435$, $\mathrm{p}=0.01$ ), and mononuclear inflammatory cells in body mucosa $(r 0.361, \mathrm{p}=0.05)$.

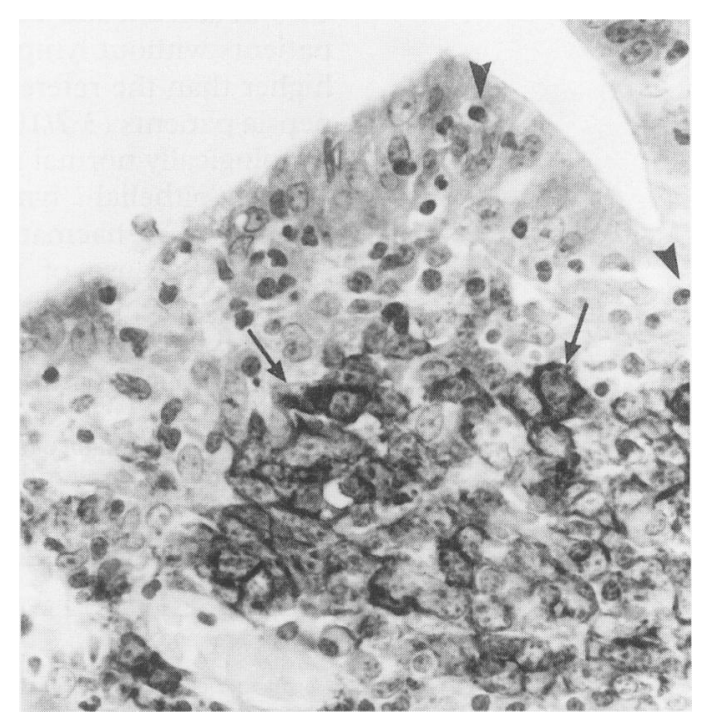

Figure 3: Lymphocytic gastritis in association with gastric lymphoma; same case as in Fig $2(A)$ and $(B)$. Lymphoma infiltration is L26 positive (arrows), but none of intraepithelial lymphocytes are stained (arrowheads). L26, magnification $\times 384$. 
TABLE II Staging of gastric lymphomas in patients with and without lymphocytic gastritis ( $L G)$. 'Unknown' category includes cases where histological specimens did not represent gastric mucosa

\begin{tabular}{llllr}
\hline Lymphoma stage & LG & No LG & Unknown & Total \\
\hline EI 1 & 1 & 3 & 3 & 7 \\
EI 2 & 3 & 7 & 2 & 12 \\
EII 1 & 0 & 2 & 2 & 4 \\
EII 2 & 0 & 0 & 0 & 0 \\
EIII & 0 & 0 & 0 & 0 \\
EIV & 2 & 2 & 0 & 4 \\
Stage unknown & 1 & 1 & 6 & 35 \\
\hline
\end{tabular}

EI 1, lymphoma confined to mucosa or submucosa. EI 2, lymphoma extending beyond submucosa. EII 1, regional lymph nodes involved. EII 2, lymph nodes involved beyond region area. EIII, involved areas on both sides of diaphragm. EIV, non-gastrointestinal organs involved.

$H$ pylori could be found in 13 of 22 patients $(59 \%)$. There were two $H$ pylori positive cases among patients with lymphocytic gastritis (29\%) and 11 among patients without $(73 \%) \quad(p=0.056$, Fisher's test). Figure 5 shows $H$ pylori status and the degree of body gastritis in cases in which both of them could be evaluated $(n=20)$. The number of $H$ pylori organisms was small in all patients (median score in patients with lymphocytic gastritis 0 , range $0-1$; median score in patients without lymphocytic gastritis 1 , range $0-2$; non-significant). The number of intraepithelial lymphocytes in body mucosa was significantly higher in $H$ pylori negative patients ( 26 median, $9-33$ range) than in $H$ pylori positive ones (10 median, 4-35 range; $p=0.048$, MannWhitney). The other clinical or histological parameters did not differ significantly between $H$ pylori positive and negative patients.

\section{Discussion}

Our retrospective study showed that lymphocytic gastritis is common in patients with primary gastric lymphoma. The frequency $(32 \%)$ is clearly higher than that reported in non-ulcer dyspepsia $(0 \cdot 8-2 \cdot 4 \%)^{34}$ and chronic active gastritis $(1 \cdot 6-4 \cdot 5 \%) .{ }^{4}$ Furthermore the number of intraepithelial lymphocytes (mean 11.9 in antrum and 10.1 in body) in lymphoma patients without lymphocytic gastritis was also higher than the reference values given for dyspepsia patients $(3 \cdot 7 / 100)^{3}$ and for patients with histologically normal mucosa $(2 \cdot 5 / 100) .{ }^{28}$

Intraepithelial lymphocytes were easily recognised in haematoxylin and eosin stained sections because of the so-called 'halo' surrounding them and their smaller nuclei compared with epithelial cells. The increase of intraepithelial lymphocytes in lymphocytic

TABLE III Localisation of lymphomas in patients with and without lymphocytic gastritis (LG). 'Unknown' category includes cases where histological specimens did not represent gastric mucosa

\begin{tabular}{llll}
\hline Lymphoma localisation & $L G$ & No LG & Unknown \\
\hline Oesophagus and cardia & 0 & 0 & 0 \\
Cardia & 0 & 0 & 2 \\
Cardia and corpus & 0 & 3 & 2 \\
Corpus & 2 & 3 & 5 \\
Corpus and antrum & 3 & 3 & 1 \\
Antrum & 0 & 4 & 0 \\
Antrum and pylorus & 1 & 2 & 0 \\
Several regions & 1 & 0 & 0 \\
Unknown & 0 & 0 & 3
\end{tabular}

TABLE IV Clinical features of lymphoma patients with and without lymphocytic gastritis (LG). No significant differences between the groups could be seen

\begin{tabular}{lll}
\hline & $L G$ & No $L G$ \\
\hline Median age (range) & $58(36-72)$ & $64(27-85)$ \\
Mean age (SD) & $57 \cdot 1(11 \cdot 0)$ & $61 \cdot 1(18 \cdot 1)$ \\
Males/females & $3 / 4$ & $8 / 7$ \\
Accompanying diseases & 1 & \\
$\quad$ Diabetes (type II) & 1 & 1 \\
Rheumatoid arthritis & 1 & 1 \\
Tuberculosis & 0 & 1
\end{tabular}

gastritis was most diffuse in surface and foveolar epithelium and was present both in antral and body mucosa as well as mucosa in the vicinity of the tumour. Lymphoepithelial lesions, which are present in mucosa associated tissue lymphomas ${ }^{23}$ were clearly different in appearance and location and could be distinguished from intraepithelial lymphocytes. Intraepithelial lymphocytes were smaller than the cells of lymphoepithelial lesions. They were evenly distributed and mostly occurred as single cells in contrast with cells of lymphoepithelial lesions, which are rather tight clusters of several cells. This discrimination between intraepithelial lymphocytes and cells of lymphoepithelial lesions was supported by the findings of immunohistochemical stainings. Most but not all intraepithelial lymphocytes stained positively with a $T$ cell antibody used (anti-CD45RO) and did not stain, in contrast with the tumour cells, with a B cell antibody L26. This shows that intraepithelial lymphocytes, being $T$ lymphocytes, ${ }^{1429}$ are not of the same cell lineage as the lymphoma cells.

Mechanisms for the increase in the number of intraepithelial lymphocytes and occurrence of lymphocytic gastritis in gastric lymphomas remain unclear. Recently, nodal B cell lymphomas with heavy increase of reactive $T$ cells have been described. ${ }^{30}$ The possibility that intraepithelial lymphocytes in our cases of gastric lymphomas represent overflow of tumour associated $\mathrm{T}$ lymphocytes seems an unlikely explanation: the excess of intraepithelial lymphocytes was present both in the proximity of lymphoma and on areas distant from the tumour, both in antral and body mucosa. Furthermore, no correlation between the size or stage of the tumour and the number of

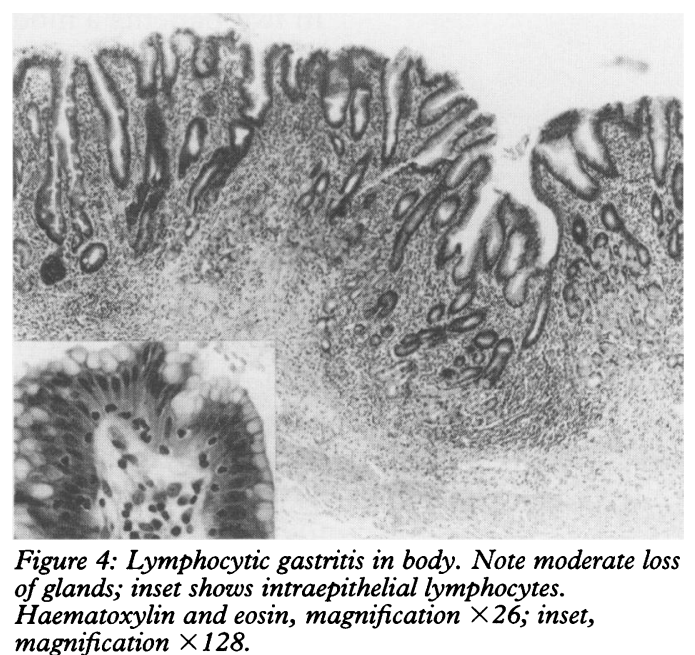




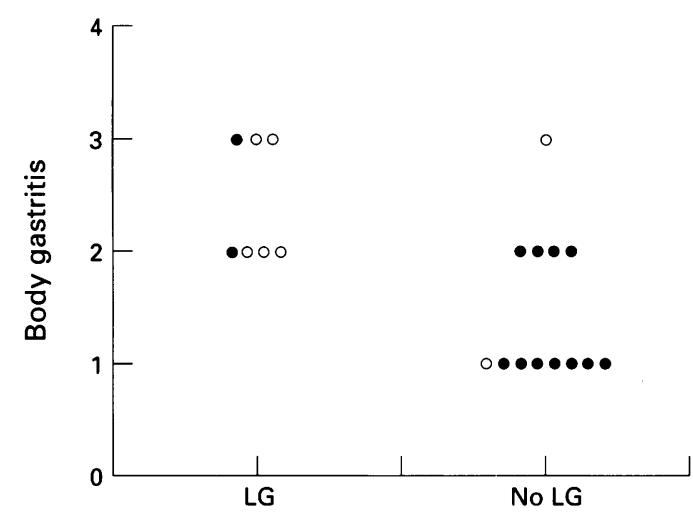

Figure 5: Grade of body gastritis and $\mathrm{H}$ pylori status in patients with and without lymphocytic gastritis $(L G)$. $\mathrm{H}$ pylori positive cases are shown as solid circles and $\mathrm{H}$ pylori negative cases as open circles.

intraepithelial lymphocytes was seen suggesting that increase of intraepithelial lymphocytes is not secondary to tumour growth. In gastric lymphomas, however, cells of the neoplastic clone may be present outside the main tumour mass among reactive inflammatory cells, ${ }^{31}$ and the possibility that lymphoma cells have some role in the development of lymphocytic gastritis cannot be totally excluded.

Gastric lymphoma, like other lymphomas of mucosa associated lymphatic tissue, are considered to develop against the background of chronic inflammation. ${ }^{13} 3233$ Recently Wotherspoon et $a l^{13}$ and Doglioni et al ${ }^{34}$ showed an association between $H$ pylori associated gastritis and gastric lymphoma; in $87-92 \%$ of the cases $H$ pylori could be detected in histological sections. In our study gastritis was present always supporting the concept of inflammation as an important background condition for gastric lymphoma, but $H$ pylori status showed an interesting pattern among patients with lymphocytic gastritis. $H$ pylori was remarkably rare among lymphoma patients with lymphocytic gastritis, only $29 \%$ (two of seven) being $H$ pylori positive, whereas $73 \%$ (11 of 15) of lymphoma cases without lymphocytic gastritis were $H$ pylori positive. Rarity of actual $H$ pylori infection in lymphoma patients with lymphocytic gastritis might be connected with more pronounced atrophic changes in body mucosa in them. Quantity of $H$ pylori in infected patients is inversely related to acid secretory capacity of body mucosa ${ }^{25}$ and serological evidence of $H$ pylori infection is common in patients with atrophic gastritis in the body while the bacterium itself is not detectable. ${ }^{35}$ Accordingly, it is possible that our $H$ pylori negative cases have been previously positive but the bacterium has disappeared together with the impairment of acid secretion from the body mucosa. No direct evidence for this assumption in this study is available as no previous biopsy specimens or serum samples were available. Interestingly, $H$ pylori is only rarely detected histologically in lymphocytic gastritis, although strong serological response is common. ${ }^{3}$

Potential common mechanisms for the simultaneous occurrence of lymphocytic gastritis and atrophy of body glands in lymphoma patients remain entirely speculative. Although intraepithelial lymphocytes are probably heterogenous in function, ${ }^{14}$ in lymphocytic gastritis they are mostly CD8 positive cells (cytotoxic/suppressor T-cells) ${ }^{36}$ and may play a part in negative regulation of immune response. Thus an increased amount of intraepithelial lymphocytes might be a reaction to abnormal antigen or an indication of abnormal regulatory mechanism of the host.

Chronic gastritis is a well known precursor of gastric cancer and cross sectional studies of cancerous stomachs have shown that the severity of the risk is related to the degree of glandular atrophy. ${ }^{37}$ For gastric lymphomas, no risk indicators of this importance are known. We suggest that lymphocytic gastritis may be a potential risk factor for gastric lymphoma. Differences in the reported mean ages in lymphocytic gastritis and lymphoma support this hypothesis; mean age of lymphocytic gastritis $(46 \cdot 5-48 \cdot 8 \text { years })^{3438}$ is less than that seen for our lymphoma patients with lymphocytic gastritis (57.1 years), or average age of gastric lymphoma in other reports (58-62 years). ${ }^{34} 39$

In summary, increase in the number of intraepithelial lymphocytes and lymphocytic gastritis is common in primary gastric lymphoma. Furthermore lymphocytic gastritis was associated with more advanced body gastritis. The reason for the rarity of $H$ pylor in the lymphoma patients with lymphocytic gastritis compared with other lymphoma patients is not known but it may be related to the atrophic changes in the body mucosa. Further studies are needed to find out whether lymphocytic gastritis is a precursor state for gastric lymphoma.

1 Haot J, Wallez L, Jouret-Mourin A, Hardy N. La gastrite 'à lymphocytes'. Une nouvelle entité? Acta Endosc 1985; 15 187-8.

2 Rubio CA, Kato Y, Sugano H. The lymphoepithelial phenomenon in the gastric mucosa. Pathol Res Pract 1985; 180: $612-4$.

3 Dixon MF, Wyatt JI, Burke DA, Rathbone BJ. Lymphocytic gastritis - relationship to Campylobacter pylori infection. gastritis - relationship to Cam

4 Jaskiewicz K, Price SK, Zak J, Louwrens HD. Lymphocytic gastritis in nonulcer dyspepsia. Dig Dis Sci 1991; 36: 1079-83.

5 Haot J, Delos M, Wallez L, Hardy N, Lenzen B, Jouret-Mourin A. Les lymphocytes intraépithéliaux en pathologie gastrique inflammatoire. Acta Endosc 1986; 16: $61-7$.

6 Karttunen T, Niemelä S. Lymphocytic gastritis and coeliac disease. F Clin Pathol 1990; 43: 436-7.

7 Hertzer NR, Hoerr SO. An interpretive review of lymphoma of the stomach. Surg Gynecol Obstet 1976; 143: 113-24.

8 Lim FE, Hartman AS, Tan EGC, Cady B, Meissner WA. Factors in the prognosis of gastric lymphoma. Cancer Factors in the progn

9 Jones RE, Willis S, Innes DJ, Wanebo HJ. Primary gastric lymphoma. Problems in staging and management. $A m \mathcal{J}$ Surg 1988; 155: 118-23.

10 Hayes J, Dunn E. Has the incidence of primary gastric lymphoma increased? Cancer 1989; 63: 2073-6.

11 Severson RK, Davis S. Increasing incidence of primary gastric lymphoma. Cancer 1990; 66: 1283-7.

12 Isaacson PG. Lymphomas of mucosa-associated lymphoid tissue (MALT). Histopathology 1990; 16: 617-9.

13 Wotherspoon AC, Ortiz-Hidalgo C, Falzon MR, Isaacson PG. Helicobacter pylori-associated gastritis and primary B-cell gastric lymphoma. Lancet 1991; 338: 1175-6.

14 Brandtzaeg P, Halstensen TS, Kett K, Krajci P, Kvale D, Rognum TO, et al. Immunobiology and immunopathology of human gut mucosa: humoral immunity and pathology of human gut mucosa. humoral immunity and intraepith.

15 Engstrand L, Scheynius A, Påhlson C. An increased number of gamma/delta T-cells and gastric epithelial cell Helicobacter pylori-associated chronic gastritis of the antrum. Am f Gastroenterol 1991; 86: 976-80. 
16 Isaacson PG, Spencer J. Commentary. Malignant lymphoma and autoimmune disease. Histopathology 1993; 22: 509-10.

17 Connors J, Wise L. Management of gastric lymphomas. Am f Surg 1974; 127: 102-8.

18 Isaacson PG, Spencer J, Wright DH. Classifying primary gut lymphomas. Lancet 1988; ii: 1148-9.

19 Carbone PP, Kaplan HS, Musshoff K, Smithers DW, Tubiana M. Report of the committee on Hodgkin's disease staging procedures. Cancer Res 1971; 31: 1860-1.

20 Musshoff K. Klinische Stadieneinteilung der NichtHodgkin Lymphome. Strahlentherapie 1977; 153: 218-21.

21 Radaskiewicz T, Dragosics B, Bauer P. Gastrointestinal malignant lymphomas of the mucosa-associated lymphoid tissue: factors relevant to prognosis. Gastroenterology 1992; 102: $1628-38$

22 Elias H, Hyde DM. Numerical density and mean caliper diameter. In: Elias H, Hyde DM. A guide to practical stereology. Vol 1. Basel: Karger, 1983: 57-82.

23 Isaacson P, Wright DH. Extranodal malignant lymphoma arising from mucosa-associated lymphoid tissue. Cancer arising from muco

24 Haot J, Hamichi L, Wallez L, Mainguet P. Lymphocytic gastritis: a newly described entity: a retrospective endoscopic and histological study. Gut 1988; 29: 1258-64.

25 Karttunen T, Niemelä S, Lehtola J. Helicobacter pylori in dyspeptic patients: quantitative association with severity of gastritis, intragastric $\mathrm{pH}$, and serum gastrin concentration. Scand f Gastroenterol 1991; 26: 124-34.

26 Price AB. The Sydney system: histological division. f Gastroenterol Hepatol 1991; 6: 209-22.

27 Marshall BJ, Warren JR. Unidentified curved bacilli in the stomach of patients with gastritis and peptic ulceration. Stomach of patients with

28 Haot J, Jouret A, Willette M, Gossuin A, Mainguet P. Lymphocytic gastritis - prospective study of its relationLymphocytic gastritis - prospective study of its relatio
ship with varioliform gastritis. Gut 1990; 31: 282-5.

29 Valnes K, Huitfeldt HS, Brandtzaeg P. Relation between T cell number and epithelial HLA class II expression quantified by image analysis in normal and inflamed human gastric mucosa. Gut 1990; 31: 647-52.

30 Macon WR, Williams ME, Greer JP, Stein RS, Collins RD, Cousar JB. T-cell-rich B-cell lymphomas. A clinicopathologic study of 19 cases. Am f Surg Pathol 1992; 16: 351-63.

31 Fend F, Schwaiger A, Weyrer K, Propst A, Mairinger T, Umlauft $\mathrm{F}$, et al. Early diagnosis of gastric lymphoma: gene rearrangement analysis of endoscopical biopsy samples. Leukemia 1994; 8: 35-9.

32 Hyjek E, Smith WJ, Isaacson PG. Primary B cell lymphoma of salivary gland and its relationship to myoepithelial sialadenitis. Hum Pathol 1988; 19: 766-76.

33 Hyjek E, Isaacson PG. Primary B cell lymphoma of the thyroid and its relationship to Hashimoto's thyroiditis. Hum Pathol 1988; 19: 1315-26.

34 Doglioni C, Wotherspoon AC, Moschini A, de Boni M, Isaacson PG. High incidence of primary gastric lymphoma in north eastern Italy. Lancet 1992; 339: phoma

35 Karnes WE Jr, Samloff IM, Siurala M, Kekki M, Sipponen $\mathrm{P}, \mathrm{Kim}$ SWR, et al. Positive serum antibody and negative tissue staining for Helicobacter pylori in subjects with atrophic body gastritis. Gastroenterology 1991; 101: 167-74.

36 Jones EA, Fléjou JF, Potet F, Muzeau F, Molas G, Rotenberg A, et al. Lymphocytic gastritis: a clinicopathological study of thirty two patients. European fournal of Gastroenterology and Hepatology 1990; 2: 367-72.

37 Sipponen $\mathrm{P}$. Atrophic gastritis as a premalignant condition. Ann Med 1989; 21: 287-90.

38 Haot J, Bogomoletz WV, Jouret A, Mainguet P. Menetrier's disease with lymphocytic gastritis. An unusual association with possible pathogenic implications. Hum Pathol 1991; 22: $379-86$.

39 Jaser N, Sivula A, Franssila K. Primary gastric nonHodgkin's lymphoma in Finland, 1972-1977. Clinical presentation and results of treatment. Scand $f$ Gastroenterol 1990; 25: 1052-9. 